\title{
Comparison of physician based reporting of tobacco attributable deaths and computer derived estimates of smoking attributable deaths, Oregon, 1989 to 1996
}

\author{
Ann R Thomas, Katrina Hedberg, David W Fleming
}

\begin{abstract}
Background-Tobacco use prevention programmes need accurate information about smoking related mortality. Beginning in 1989, Oregon began asking physicians to report on death certificates whether tobacco use contributed to the death.

Objective-To determine the long term comparability of this method of estimating tobacco attributable mortality to estimates of smoking attributable mortality derived from a computer model.

Design-For the period 1989 to 1996, we compared mortality resulting from tobacco use reported by Oregon physicians to estimates of smoking attributable deaths (SADs) derived by "Smoking attributable mortality, morbidity and economic costs" software version 3.0 (SAMMEC 3.0), a widely used software program that estimates SADs on the basis of smoking prevalence and relative risks of specific diseases among current and former smokers.
\end{abstract}

Main outcome measures-Numbers of deaths, age, sex, and category of disease.

Results-Of 212448 Oregon deaths during 1989-1996, SAMMEC 3.0 estimated that $42778(20.1 \%)$ were attributable to cigarette smoking. For the same 27 diagnoses, physicians reported that tobacco contributed to $42839 \quad(20.2 \%)$ deaths-a cumulative difference of only 61 deaths over the eight year period. The age and sex distributions of tobacco and smoking attributable deaths reported by the two systems were also similar. By category of disease, the ratio of SAMMEC 3.0 estimates to physician reported deaths was $\mathbf{1 . 1 1}$ for neoplasms, $\mathbf{0 . 8 8}$ for heart disease, and $\mathbf{1 . 0 4}$ for respiratory disease.

Conclusions-Physician reporting provides comparable estimates of smoking attributable mortality and can be a valuable source of data for communicating the risks of tobacco use to the public. (Tobacco Control 2001;10:161-164)

Keywords: mortality; prevention; control; cause of death; population surveillance

Ann Thomas, MD, MPH, Oregon Health Division, 800 NE Oregon Street, Suite 772 Portland, OR 97232, USA ann.thomas@state.or.us

Received 12 January 2000 and in revised form

11 August 2000. Accepted 2 February 2001 resources to tobacco prevention, controversy over the actual burden of disease from tobacco and the merit of funding tobacco prevention programmes will arise. Not only do public health officials need to quantify the burden of smoking related mortality accurately, they must convey these numbers to legislators and the public in a convincing manner. The Centers for Disease Control and Prevention's "Smoking-attributable mortality, morbidity and economic costs" software version 3 (SAMMEC 3.0) is a widely used software program that estimates smoking attributable deaths (SADs). ${ }^{1}$ For purposes of public health advocacy and education, however, physician reports may be more believable to the public than estimates derived from computer models.

In 1989, Oregon became the first of nine states or cities (Colorado, Louisiana, Maryland, Nebraska, North Dakota, Oregon, Texas, Utah, and New York City) to ask physicians to report on death certificates whether tobacco use contributed to the death. A preliminary comparison of SADs derived from SAMMEC 3.0 and tobacco attributable deaths reported by Oregon physicians found similar results using both methods. ${ }^{2}$ However, whether this finding would persist over time has remained questionable. The objective of this study was to determine the long term comparability of physician reporting as a method of estimating smoking attributable mortality.

\section{Methods}

PHYSICIAN REPORTS

When completing death certificates, physicians first list the underlying or primary cause of death, followed by contributory causes, or secondary conditions that may have contributed to the death. Since January 1989, Oregon death certificates have included the question: "Did tobacco use contribute to the death?" Physicians are required to check one of four possible responses: yes, probably, no, or unknown. Health division personnel routinely contact the certifying physician when a box is not checked, or the response does not appear logical; for the period 1989 to 1996, fewer than $1 \%$ of death certificates required physician follow up. For the purpose of this analysis, we defined physician reported, tobacco attributable deaths (TADs) as deaths among persons for whom physicians reported that tobacco contributed to or probably contributed to their deaths. (Although physician reporting differs from SAMMEC 3.0 in that it measures mortality caused by tobacco, while SAMMEC 
Table 1 Smoking prevalence (\%) among male and female current and former smokers, aged 35-64 years and 65 and older, and pregnant women, Oregon, 1988-1995

\begin{tabular}{lllllllll}
\hline & 1988 & 1989 & 1990 & 1991 & 1992 & 1993 & 1994 & 1995 \\
\hline $\begin{array}{l}\text { Males } \\
\text { 35-64 years }\end{array}$ & & & & & & & & \\
$\quad$ Current & 26.5 & 27.9 & 27.7 & 27.0 & 22.2 & 25.7 & 23.7 & 25.4 \\
$\quad$ Former & 41.9 & 40.8 & 40.7 & 39.4 & 40.2 & 38.9 & 38.2 & 32.7 \\
$\begin{array}{l}\text { 65 years } \\
\text { Current }\end{array}$ & 12.6 & 11.3 & 11.3 & 12.8 & 10.1 & 10.3 & 9.6 & 8.2 \\
$\quad$ Former & 59.2 & 63.0 & 65.1 & 59.7 & 55.5 & 59.2 & 64.5 & 61.1 \\
$\begin{array}{l}\text { Females } \\
\text { 35-64 years }\end{array}$ & & & & & & & & \\
$\quad$ Current & 25.7 & 23.1 & 22.0 & 20.9 & 23.0 & 20.0 & 21.5 & 20.9 \\
$\quad$ Former & 23.9 & 27.7 & 26.8 & 30.0 & 26.0 & 28.4 & 28.2 & 29.6 \\
$\begin{array}{l}\text { 65 years } \\
\text { Current }\end{array}$ & 12.1 & 11.8 & 13.7 & 12.8 & 11.1 & 11.0 & 14.0 & 14.9 \\
$\quad$ Former & 27.4 & 29.7 & 24.7 & 26.9 & 27.5 & 34.8 & 24.9 & 29.4 \\
$\quad$ Maternal & $23.8 \star$ & 23.8 & 22.4 & 21.4 & 20.5 & 18.9 & 18.2 & 17.8 \\
\hline
\end{tabular}

* Oregon birth certificates did not collect information on maternal smoking until 1989, so the 1989 estimate of maternal smoking was also used in the analysis for 1988 .

3.0 measures mortality attributable only to cigarette smoking, we expect that the number of additional deaths from use of smokeless tobacco, pipes and cigars to be small. The US Bureau of the Census conducts the Current Population Survey, which reported that $2.8 \%$ of Oregon adults used smokeless tobacco, $0.9 \%$ smoked a pipe, and $0.6 \%$ smoked cigars in 1992-93. In 1995-96, $2.8 \%$ of Oregon adults used smokeless tobacco, $0.4 \%$ smoked a pipe, and $0.7 \%$ smoked cigars (http:// www2.cdc.gov/nccdphp/osh/state/).)

\section{SAMMEC 3.0 ESTIMATES}

SAMMEC 3.0 estimates the number of smoking attributable deaths by using attributable risk formulas based on cigarette smoking prevalence and relative risks for 27 underlying causes of death among current and former smokers. ${ }^{1}$ For 25 of the underlying causes of death, SAMMEC 3.0 uses a single age adjusted relative risk estimate to calculate the attributable risk for male and female current and former smokers (that is, a different risk estimate is used for male current smokers, male former smokers, female current smokers, and female former smokers). For the remaining two causes of death, ischaemic heart disease and cerebrovascular disease, SAMMEC 3.0 additionally utilises different relative risk estimates for two age groups: for persons 35-64 years of age, and for persons 65 years and older. We generated annual SAD estimates for Oregon residents using 1989-1996 Oregon death certificate data and rates of smoking prevalence among current and former smokers from the 1988-1995 Oregon behavioural risk factor survey (table 1). Annual prevalence of

Table 2 Comparison of SAMMEC 3.0 estimated smoking attributable deaths (SADs) and physician reported tobacco attributable deaths (TADs), by underlying cause of death, Oregon, 1989-1996

\begin{tabular}{|c|c|c|c|c|}
\hline Disease $\left(I C D-9^{\star}\right.$ code $)$ & All deaths & $\begin{array}{l}\text { SAMMEC } 3.0 \\
\text { estimates of } S A D \text { s } \\
(\%)\end{array}$ & $\begin{array}{l}\text { Physician reports } \\
\text { of TADs (\%) }\end{array}$ & $\begin{array}{l}\text { SAMMEC 3.0: } \\
\text { physician ratio }\end{array}$ \\
\hline \multicolumn{5}{|l|}{ Neoplasms } \\
\hline Lip, oral cavity, pharynx (140-149) & 752 & $578(76.9)$ & $460(61.2)$ & 1.26 \\
\hline Oesophagus $(150)$ & 1063 & $803(75.5)$ & $406(38.2)$ & 1.98 \\
\hline Pancreas (157) & 2701 & $653(24.2)$ & $287(10.6)$ & 2.28 \\
\hline Larynx (161) & 299 & $254(84.9)$ & $232(77.6)$ & 1.09 \\
\hline Trachea, lung, bronchus (162) & 15328 & $12480(81.4)$ & $12245(79.9)$ & 1.02 \\
\hline Cervix uteri (180) & 355 & $109(30.7)$ & $29(8.2)$ & 3.76 \\
\hline Urinary bladder (188) & 1117 & $427(38.2)$ & $343(30.7)$ & 1.24 \\
\hline Kidney, other urinary (189) & 1103 & $336(30.5)$ & $126(11.4)$ & 2.67 \\
\hline Total & 22628 & $15640(69.1)$ & $14128(62.4)$ & 1.11 \\
\hline \multicolumn{5}{|l|}{ Cardiovascular diseases } \\
\hline Hypertension (401-404) & 3105 & $495(15.9)$ & $528(17.0)$ & 0.94 \\
\hline Ischaemic heart disease $(410-414)$ & 41911 & 8577 (20.5) & $11423(27.3)$ & 0.75 \\
\hline Other heart disease $+(390-398,415-417,420-429)$ & 16086 & $2667(16.6)$ & $2696(16.8)$ & 0.99 \\
\hline Cerebrovascular disease $(430-438)$ & 17771 & $2531(14.2)$ & $2565(14.4)$ & 0.99 \\
\hline Atherosclerosis (440) & 2503 & $947(37.8)$ & $522(20.9)$ & 1.81 \\
\hline Aortic aneurysm (441) & 1815 & $805(44.4)$ & $578(31.8)$ & 1.39 \\
\hline Other arterial disease (442-448) & 1043 & $412(39.5)$ & $294(28.2)$ & 1.40 \\
\hline Total & 84234 & $16434(19.5)$ & $18606(22.1)$ & 0.88 \\
\hline \multicolumn{5}{|l|}{ Respiratory diseases } \\
\hline Pneumonia, influenza (480-487) & 7266 & $1824(25.1)$ & $1127(15.5)$ & 1.62 \\
\hline Bronchitis, emphysema (490-492) & 2898 & $2335(80.6)$ & $2498(86.2)$ & 0.93 \\
\hline Chronic airways obstruction (496) & 7632 & $6138(80.4)$ & $6138(80.4)$ & 1.0 \\
\hline Other respiratory diseases $\ddagger(10-12,493)$ & 790 & $191(24.2)$ & $276(34.9)$ & 0.69 \\
\hline Total & 18586 & $10488(56.4)$ & $10039(54.0)$ & 1.04 \\
\hline \multicolumn{5}{|l|}{ Perinatal conditions } \\
\hline Short gestation/low birth weight $(765)$ & 177 & $25(14.1)$ & $8(4.5)$ & 3.13 \\
\hline Respiratory distress syndrome (769) & 97 & $13(13.4)$ & $6(6.2)$ & 2.17 \\
\hline Respiratory conditions: newborn (770) & 120 & $17(14.2)$ & $3(2.5)$ & 5.67 \\
\hline Sudden infant death syndrome (798.0) & 649 & $61(9.4)$ & 0 & - \\
\hline Total & 1043 & $116(11.1)$ & $17(1.6)$ & 6.82 \\
\hline Burns (890-899) & 312 & $100(32.1)$ & $49(15.7)$ & 2.04 \\
\hline All smoking related deaths & 126803 & $42778(33.7)$ & $42839(33.8)$ & 1.0 \\
\hline $\begin{array}{l}\text { All other deaths (not considered by SAMMEC } 3.0 \text { to } \\
\text { be related to smoking) }\end{array}$ & 85645 & - & $7743(9.0)$ & - \\
\hline Total & 212448 & $42778(20.1)$ & $50582(23.8)$ & 0.85 \\
\hline
\end{tabular}

${ }^{\star}$ International classification of diseases, $9^{\text {th }}$ edition.

tCombines deaths from rheumatic heart disease, pulmonary heart disease, and cardiac arrest/other heart disease.

$\ddagger$ Combines deaths from respiratory tuberculosis and asthma. 


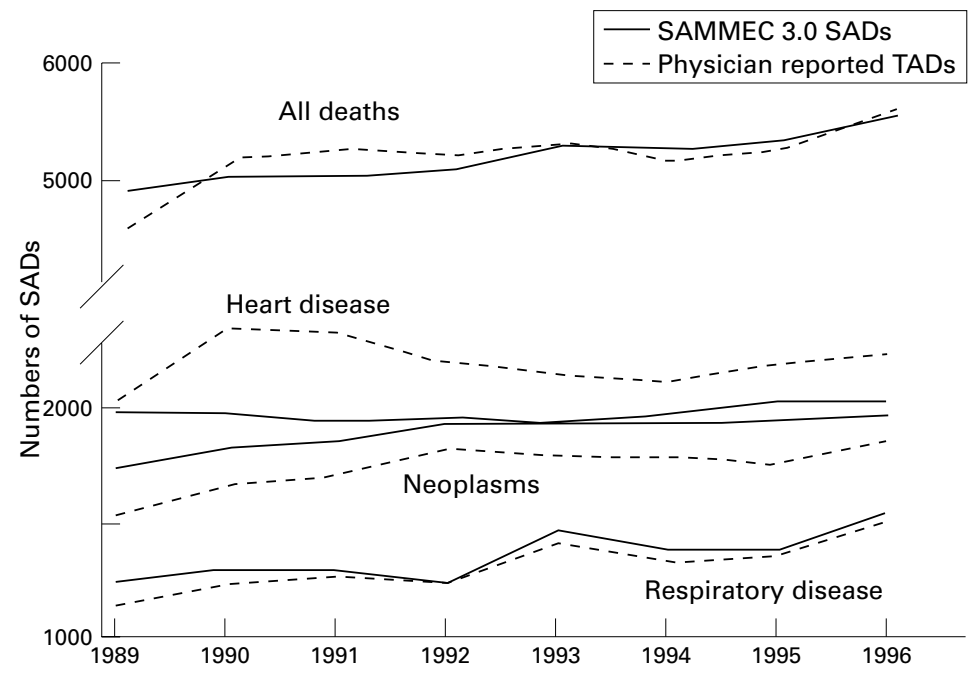

Figure 1 Annual numbers of smoking attributable deaths (SADs) estimated by SAMMEC 3.0 and physician reported tobacco attributable deaths (TADs) on death certificates, Oregon, 1989-1996. For raw data visit wwww.tobaccocontrol.com.

maternal smoking was taken from birth certificates (table 1).

COMPARISON OF SAMMEC 3.0 ESTIMATES AND PHYSICIAN REPORTS

Because SAMMEC 3.0 uses only 27 underlying causes of death to estimate SADs, we first compared SAMMEC 3.0 estimates of SADs with those physician reported TADs where the underlying cause of death fell into an aetiologic category recognised by SAMMEC 3.0. We next examined physician reported deaths for which the underlying cause of death was not recognised by SAMMEC 3.0 to determine whether the contributing causes of death were related to smoking. The latter analysis was performed only for the period 1993-1996, years for which contributing causes of death were coded in the Oregon vital records mainframe database.

\section{Results}

During the time period 1989-1996, 126803 $(59.7 \%)$ of 212448 Oregon deaths had underlying causes of death recognised by SAMMEC 3.0 as linked to smoking (table 2). Of these 126803 deaths, SAMMEC 3.0 estimated that $42778(33.7 \%)$ were attributable to smoking. For the same diagnoses, physicians reported that tobacco contributed to 42839 (33.8\%) deaths, a cumulative difference of only 61 deaths over the eight year period. For each year, the ratio of SAMMEC 3.0 estimates to

Table 3 Comparison of deaths with and without contributing causes of death related to smoking, among deaths where underlying cause of death not related to smoking, Oregon, 1993-1996 $(n=46,321)$.

\begin{tabular}{llll}
\hline & \multicolumn{2}{l}{$\begin{array}{l}\text { Physicians reported that tobacco contributed to } \\
\text { the death? }\end{array}$} \\
\cline { 2 - 4 } & $\begin{array}{l}\text { Yes } \\
n(\%)\end{array}$ & $\begin{array}{l}\text { No } \\
n(\%)\end{array}$ & $\begin{array}{l}\text { Relative risk } \\
(95 \% \text { CI })\end{array}$ \\
\hline $\begin{array}{llll}\text { Deaths where contributing cause of death } \\
\text { related to smoking }\end{array}$ & $\begin{array}{l}2227 \\
(64.0)\end{array}$ & $\begin{array}{l}10499 \\
(24.5)\end{array}$ & $2.61(2.54$ to 2.69) \\
$\begin{array}{l}\text { Deaths where contributing cause of death not } \\
\text { related to smoking }\end{array}$ & $\begin{array}{l}1250 \\
(36.0)\end{array}$ & $\begin{array}{l}32345 \\
(75.5)\end{array}$ & - \\
Total & 3477 & 42844 & - \\
\hline
\end{tabular}

CI, confidence interval. physician reported deaths ranged from 1.07-0.95 (fig 1). SAMMEC 3.0 estimates of deaths from neoplasms were only slightly higher than physician reported deaths from these causes; the average ratio of SAMMEC 3.0 estimates to physician reports was 1.11 with a range of 1.07-1.17. SAMMEC 3.0 generated slightly lower numbers of deaths from heart disease than those reported by physicians (average ratio 0.88, range $0.80-0.98$ ). Deaths from respiratory disease estimated by SAMMEC 3.0 most closely matched the numbers reported by physicians, with an average ratio of 1.04 (range 1.02-1.11). Finally, although not shown by year, the overall ratio of SAMMEC 3.0 estimates of SADs to physician estimates of TADs from perinatal conditions and burn deaths was 6.82 and 2.04, respectively (table 2 ).

The sex and age distributions of tobacco and smoking attributable deaths reported by the two systems were also remarkably similar. Physicians reported that $61.6 \%$ of TADs occurred among men compared with SAMMEC 3.0's estimate of $62.6 \%$. By year, physician reported deaths in men differed from SAMMEC estimates by $\leqslant 3 \%$. Overall, the median age at death for TADs reported by physicians was 73 and by year was either 72 or 73 . For SAMMEC 3.0, the median age of death was 74 overall and ranged from $73-75$ by year.

Lastly, we examined the 46321 deaths during the period 1993-1996 that did not have an underlying cause of death recognised by SAMMEC 3.0 as aetiologically linked to smoking (table 3). During 1993-1996, physicians reported that $3477(7.5 \%)$ of these deaths were related to tobacco. Of these 3477 physician reported deaths, $2227(64.0 \%)$ listed a contributing, or secondary, cause of death that fell into one of the 27 SAMMEC 3.0 categories; this proportion was similar by year (range 62.3-65.6\%). Compared with other deaths from underlying causes of death not recognised by SAMMEC 3.0 that physicians did not link to tobacco, deaths reported by physicians as related to tobacco were more than twice as likely to have a contributing cause of death aetiologically linked to tobacco. Additionally, we reviewed the underlying causes of death for the 1250 deaths that physicians reported were linked to tobacco but that did not have an underlying or contributory cause of death that fell into one of the 27 SAMMEC 3.0 categories. Four hundred and seventy one $(37.1 \%)$ fell into the general category of neoplasms (International classification of diseases, ninth revision (ICD-9) codes 140-239), but no single cancer predominated. The remaining 729 deaths were widely distributed over a range of underlying causes of death, including digestive diseases (ICD-9 codes 520-579), mental disorders (ICD-9 codes 290-319), and endocrine, nutritional, and metabolic diseases and immunity disorders (ICD-9 codes 240-279). 
Discussion

For the 27 SAMMEC diagnoses, SAMMEC 3.0 and physician reports provided similar estimates over the entire eight year period, suggesting that physician reporting and SAMMEC 3.0 are comparable methods of estimating smoking attributable mortality. Small discrepancies did exist: SAMMEC 3.0 estimated more deaths from neoplasms, whereas physicians reported more deaths from heart disease. Although physician estimates of deaths from lung cancer closely matched those produced by SAMMEC 3.0, they greatly underestimated SADs from cervical, oesophageal, and pancreatic cancer, suggesting a lack of knowledge of the link between smoking and these conditions. The multifactorial nature of heart disease makes it difficult to assign the specific risk factor responsible for the death on an individual basis, possibly leading physicians to overestimate the role of tobacco in this condition. Alternatively, physician reporting on death certificates may be more accurate than SAMMEC 3.0 for cardiovascular deaths; physicians are more sensitive to a patient's history of smoking behaviour and of the relation between smoking, age, and other comorbidities that are also smoking related that may have contributed to the patient's death.

SAMMEC 3.0 also estimated higher numbers of deaths from perinatal conditions and burn deaths than physicians reported. Although deaths from these conditions comprised less than $0.01 \%$ of SADs estimated by either method and did not greatly affect overall mortality estimates, it is interesting to note that physicians appear reluctant to attribute deaths from these conditions to tobacco use. It may be that physicians may not consider the role of tobacco when the deceased is not a smoker, as may happen when an infant dies of sudden infant death syndrome or the family member of a smoker dies in a fire in the home. Physicians' systematic under reporting of deaths from certain categories of deaths such as burns, perinatal conditions, and non-lung neoplasms points to the need for both medical education and media and public awareness campaigns that draw more attention to the role of tobacco in these conditions.

In some instances, physician reporting on death certificates may be more accurate than estimates derived by SAMMEC 3.0. One shortfall of SAMMEC 3.0 is its inability to consider contributing causes of death in estimating SADs. Our review of physician reported TADs from underlying causes of death not recognised by SAMMEC 3.0 found that most had a contributing cause of death that could be linked to cigarette smoking, suggesting that physician reports may result in a better estimate of smoking related mortality. Secondly, SAMMEC 3.0 estimates are based on current estimates of the prevalence of current and former smokers. After quitting

\section{What this paper adds}

In 1989, the state of Oregon began to ask physicians to report on death certificates whether tobacco use contributed to the death. Two years after the programme had been implemented, a preliminary comparison of smoking attributable deaths (SADs) calculated using a widely used computer program and tobacco attributable deaths reported by Oregon physicians found similar results using both methods. However, no studies have evaluated the long term comparability of these two methods.

Thomas and colleagues reproduced the earlier study over a longer time period. From 1989 to 1996, there were 42778 SADs in Oregon, according to the software program. For the same diagnoses, Oregon physicians reported that tobacco contributed to 42839 deaths - a cumulative difference of only 61 deaths over the eight year period. Physician reports can be a valuable source of data for estimating smoking attributable mortality and, for purposes of public health advocacy and education, may be more believable to the public than estimates derived from computer models.

smoking, the risk of death from the 27 underlying causes of death falls at different rates for the different diseases, and SAMMEC 3.0 does not take into consideration the length of time since the individual quit smoking. Physicians are in a better position to utilise cessation information, while SAMMEC 3.0 is fairly inflexible in this regard. For tracking smoking attributable mortality in settings where anti-smoking programmes have been implemented and smoking prevalence is changing rapidly, physician reporting may be more valid.

Finally, physician reporting can be a valuable source of data for risk communication to the public. Persuading legislators or the public that tobacco prevention programmes deserve public funding requires convincing evidence of the burden of smoking attributable morbidity and mortality. Estimates derived locally from trusted sources (for example, physicians) may be more useful for this purpose than from methods considered more methodologically sound by epidemiologists.

The authors would like to thank Thomas Torok, MD, MPH for his thoughtful review of the manuscript.

1 Centers for Disease Control and Prevention. SAMMEC 3.0.0 (Smoking-attributable mortality, morbidity, and economic costs): computer software and documentation. Atlanta: for Disease Control and Prevention, Office on Smoking and Health, 1996.

2 McAnulty JM, Hopkins DD, Grant-Worley JA, et al. A comparison of alternative systems for measuring smokingattributable deaths in Oregon, USA. Tobacco Control 1994; 3:115-9. 